\title{
Prevalence of Hypertension among Adults Residing In Urban Slums of Ramnagar, Belgaum City-A Cross-Sectional Study
}

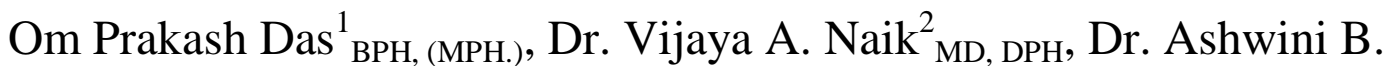 \\ Narasannavar ${ }^{3}$ BDS, MPH Ram Kumar Sah ${ }_{\text {BPH, (MPH.) }}$ \\ ${ }^{I}$ Department of Public Health J.N. Medical College, KLE University, Belgaum, Karnataka, India \\ ${ }^{2}$ Head of the Department of Public Health, J.N. Medical College, KLE University, Belgaum, Karnataka, India \\ ${ }^{3}$ Lecturer, Department of Public Health, J.N. Medical College, KLE University, Belgaum, Karnataka, India \\ ${ }^{4}$ Department of Public Health J.N. Medical College, KLE University, Belgaum, Karnataka, India
}

\begin{abstract}
Hypertension is a global public health challenge and major risk factor for cardiovascular mortality. It is third leading silent killer which is affecting 1 billion adults and is estimated to cause 7.1 million deaths annually. India being low \& middle income country and larger proportion of population are living in urban slum where overcrowding and standard of living are due to this, prevalence of hypertension is more, and have a major impact on health and health care. Therefore, it is important to find the prevalence of hypertension among adults residing in urban slum of Ramnagar, Belgaum city. A cross-sectional community based study among 364 adults of aged 20-59 years in urban slum. The anthropometric measurement and blood pressure was taken according to WHO criteria. The data was analyzed by using percentage for prevalence and Chi-square test was used to find out the association. The overall prevalence of hypertension was found to be $90(24.7 \%)$. Majority of the hypertensive (60.4\%) were seen in the age group between 50-59 years. The higher prevalence of hypertension was found with overweight (37.5\%, obesity (48.6\%), extra salt intake (30\%), lack of physical exercise (22.9\%), saturated fat intake (29.6\%), non-vegetarian diet (24.5\%) and shown significant association. Prevalence of hypertension was high among adults. Advancing age, sex, lack of physical exercise, BMI were found to be important factors contributing to the causation of hypertension. Therefore, preventive programs are necessary to tackle the rising burden of hypertension.
\end{abstract}

Key words: Hypertension, Risk factors, Urban Slum, Body Mass Index

\section{Introduction}

Hypertension is a global public health problem affecting $26 \%$ ( 1 billion) adult population worldwide in the year $2000 .{ }^{1}$ It is estimated to cause 7.1 million deaths annually accounting for $13 \%$ of all deaths and it is projected to increase to $29.2 \%$ by the year $2025 .{ }^{2}$ It is an enormous health problem and is one of the biggest health challenges in the $21^{\text {th }}$ century and third leading silent killer in the world and one in three adults are found hypertensive worldwide. ${ }^{3,4}$

In developed countries it is 4th leading cause of premature death, whereas in developing countries it is $7^{\text {th }}$ leading cause of premature death. ${ }^{3,5}$ Hypertension is largely ignored as a public health problem in developing countries, because of the asymptomatic nature of the condition. ${ }^{6}$ In India hypertension is emerging as a major public health problem and is more prevalent among urban compared to those of rural people. ${ }^{7}$

In urban India almost $35 \%$ of the people are hypertensive. It is the commonest cardiovascular disease, posing a major public health challenge and is due to the consequence of urbanization, change in life style pattern, diet, stress and the overall socio-economic and epidemiological transition. ${ }^{6}$

As India is still on the path of development, many rural people are shifting to urban area. Hence there are large numbers of people living in urban slums which are overcrowded and their standard of living is poor. Because of these factors people are at risk of hypertension in slum area and there are very few studies done in these areas, so the present study is undertaken to find out the prevalence of hypertension in adults in the community setting of urban slum and preventive strategies can be planned to promote health among all sections of the population after assessing risk factors leading to hypertension.

\section{Material And Methods}

A Cross-sectional study was conducted among adults aged 20-59 years in catchment of Urban Health Centre Ramnagar, Belgaum city for a period of 9 months (i.e. January to September 2013). The sample size was calculated by using formula $\mathrm{n}=\mathrm{z}^{2} \mathrm{pq} / \mathrm{d}^{2}$ (Where, $\mathrm{p}=35 \%$, absolute error $\mathrm{d}=5 \%$ ). Thus sample size was calculated as 364. This study included all participants who gave the written informed consent and were residing at least from one year in the Ramanagar. The adults who were pregnant and ill during data collection were excluded for this study. Systematic random sampling was used (i.e. sampling Interval= total household/ total 
sample size $=3245 / 364=8.91 \approx 9$, so $8^{\text {st }}$ house was selected by simple random sampling and every $9^{\text {th }}$ house was taken) to select the sample. Pre- designed and pre- tested questionnaire was used to collect information regarding socio-demographic characteristics, dietary habits and history regarding diseases. Anthropometric measurement and blood pressure were measured using standard techniques. Ethical clearance was obtained from Institutional Ethics committee of J. N. Medical College, KLE University Belgaum, Karnataka, India. All the data were entered into SPSS-20 version and analyzed at 5\% level of significance and interpreted by using descriptive and inferential statistics.

\section{Results}

This study was conducted among 364 adults of urban slums of Ramnagar. Among them, 170(46.7\%) were males and $194(53.3 \%)$ were females. $58.5 \%$ of participants were literates. $9.3 \%$ were in business, $17.3 \%$ were in service, $17 \%$ were labourers, $9.1 \%$ were students, $33.2 \%$ were housewives, $10.4 \%$ were driver and $3.6 \%$ were not working. $12.9 \%$ were unmarried, $82.7 \%$ had married. $63.2 \%$ belonged to nuclear family, $56 \%$ belonged to class II followed 37.4\% Class III, according to Modified B. G. Prasad classification of socioeconomic status. The overall prevalence of hypertension was found to be $24.7 \%$. Out of the total hypertensive, $80.7 \%$ were known cases of hypertension and taking medication. Only $14.3 \%$ of hypertensive was newly diagnosed cases of hypertension. The prevalence of hypertension was significantly associated with age, sex, family history and BMI (TABLE: 1). As the age increases the prevalence of hypertension steadily increases. Prevalence of hypertension was significantly higher in female, positive family history of parents and obese participants.

TABLE No. 1: Prevalence of Hypertension by various risk factors

\begin{tabular}{|c|c|c|c|c|c|c|c|c|}
\hline \multirow[t]{2}{*}{ Variables } & \multicolumn{2}{|c|}{$\begin{array}{c}\text { Normotensive } \\
(n=274)\end{array}$} & \multicolumn{2}{|c|}{$\begin{array}{l}\text { Hypertensive } \\
\qquad(\mathrm{n}=90)\end{array}$} & \multicolumn{2}{|c|}{$\begin{array}{c}\text { Total } \\
(\mathbf{N}=364)\end{array}$} & \multirow[t]{2}{*}{$\chi^{2}$ Value } & \multirow[t]{2}{*}{ P Value } \\
\hline & No. & $\%$ & No & $\%$ & No & $\%$ & & \\
\hline \multicolumn{9}{|l|}{ Age in years } \\
\hline $20-29$ & 99 & 94.3 & 6 & 5.7 & 105 & 28.85 & & \\
\hline $30-39$ & 82 & 92.1 & 7 & 7.8 & 89 & 24.45 & 96.7 & $0.001 *$ \\
\hline $40-49$ & 57 & 72.2 & 22 & 27.8 & 79 & 21.70 & & \\
\hline $50-59$ & 36 & 39.6 & 55 & 60.4 & 91 & 25.00 & & \\
\hline \multicolumn{9}{|l|}{$\underline{\operatorname{Sex}}$} \\
\hline$\overline{\text { Male }}$ & 136 & 80.0 & 34 & 20.0 & 170 & 46.7 & 3.827 & $0.043^{*}$ \\
\hline Female & 138 & 71.1 & 56 & 28.8 & 194 & 53.3 & & \\
\hline \multicolumn{9}{|l|}{ Family history } \\
\hline Father & 22 & 55 & 18 & 45 & 40 & 10.99 & & \\
\hline Mother & 3 & 42.9 & 4 & 57.1 & 7 & 1.92 & 32.285 & $0.001 *$ \\
\hline Absent & 198 & 84.6 & 36 & 15.4 & 234 & 64.29 & & \\
\hline Unaware & 51 & 61.4 & 32 & 38.6 & 83 & 22.8 & & \\
\hline \multicolumn{9}{|l|}{$\underline{\text { BMI }}$} \\
\hline Underweight & 27 & 87.1 & 4 & 12.9 & 31 & 8.52 & & \\
\hline Normal & 166 & 86.9 & 25 & 13.1 & 191 & 52.47 & & \\
\hline Overweight & 45 & 62.5 & 27 & 37.5 & 72 & 19.78 & 43.923 & $0.001 *$ \\
\hline Obesity & 36 & 51.4 & 34 & 48.6 & 70 & 19.23 & & \\
\hline
\end{tabular}

$57.1 \%$ had consumed mixed diet, $22 \%$ had consumed extra salt and only $7.4 \%$ had consumed saturated oil in their diet. $14.8 \%$ participants had the habit of alcohol consumption and $9.9 \%$ had smoking habits, $12.9 \%$ of participants had family history of hypertension and $39 \%$ participants had BMI $\geq 25$ and $31.6 \%$ were found to have abdominal obesity. Association between prevalence of hypertension and dietary pattern is shown in the TABLE 2.

TABLE NO. : 2 Prevalence of hypertension and dietary pattern

\begin{tabular}{|c|c|c|c|c|c|}
\hline \multirow[t]{2}{*}{ *Diet habit } & \multicolumn{2}{|c|}{ Normotensive } & \multicolumn{2}{|c|}{ Hypertensive } & \multirow[t]{2}{*}{ Total } \\
\hline & No. & $\%$ & No. & $\%$ & \\
\hline Vegetarian & 117 & 75.0 & 39 & 25.0 & 156 \\
\hline Mixed & 157 & 75.5 & 51 & 24.5 & 208 \\
\hline \multicolumn{6}{|l|}{ **Salt intake } \\
\hline Extra salt intake & 56 & 70.0 & 24 & 30.0 & 80 \\
\hline No extra salt intake & 218 & 76.6 & 66 & 23.2 & 284 \\
\hline \multicolumn{6}{|l|}{$* * *$ Type of oil consumed } \\
\hline Saturated & 19 & 70.4 & 8 & 29.6 & 27 \\
\hline Unsaturated & 255 & 75.7 & 82 & 24.3 & 337 \\
\hline Total & 274 & 75.3 & 90 & 24.7 & 364 \\
\hline
\end{tabular}




\section{Discussion}

In this study the overall prevalence of hypertension was found to be $24.7 \%$ in adults aged $20-59$ years. The prevalence was less when compared to the studies conducted at Puducherry, Delhi, Bombay and Chennai where the prevalences were $27.6 \%, 27.5 \%, 36.4 \%$ and $39.17 \%$ respectively. ${ }^{6,13,15,16}$ On the contrary there were studies conducted at Durban, Tirupati, Bangalore and Mumbai where the prevalence was lower than the present study that is $19 \%, 8.6 \%$ and $8.6 \%$ respectively. ${ }^{8,9,10,14}$ This variation could be because hypertension is a life style disease and the prevalence is more when there is risk behaviour.

The prevalence of hypertension was high $(60.4 \%)$ in the age group of 50-59 years and was increasing steadily with age which was comparable with studies conducted in Coastal Karnataka in 2013 and Jamnagar in $201{ }^{3,12}$ The prevalence of hypertension was more in females $(28.8 \%)$ than the males $(20 \%)$. Few studies conducted in Mumbai showed that the prevalence of hypertension was high in females than in males which was similar to our findings. ${ }^{14,15} 46.8 \%$ of hypertensive had the family history of hypertension, $21.4 \%$ did not have family history of hypertension. The results were statistically significant with family history of hypertension. Few studies conducted in Tirupati and Puducherry revealed that family history of hypertension is a risk factor for hypertension $\left(23.3 \%\right.$ and $24.4 \%$ respectively). The results were statistically significant. ${ }^{6,8}$ In our study, higher prevalence of hypertension was found $42.9 \%$ ( overweight $37.5 \%$ \& obesity $48.6 \%$ ) whose BMI was $\geq$ 25 which were statistically significant and was similar to the study conducted in Puducherry. ${ }^{6}$ This study showed prevalence of hypertension was significantly associated with diet habit which was similar to the study conducted in puducherry but did not significant with extra salt intake and type of oil consumed which was similar to the study conducted Tirupati. ${ }^{6,8}$

\section{Conclusion}

The prevalence of hypertension was $24.7 \%$ among adults aged 20-59 years. The various risk factors like age, sex, family history and BMI were also found to be significantly associated with hypertension among adults. Further large scale studies need to be done to establish the relationship between physical exercise, dietary habits, smoking etc.

\section{Acknowledgement}

I am grateful to our Department of Public Health, J.N. Medical College, KLE University, Belgaum, all the study participants and all of my friends who helped me directly and indirectly in this research work.

Conflict of Interest: None Declared. Source of support: Nil.

\section{References}

[1]. Baliga R.R. \& Narula J. "Salt never calls itself sweet”. Indian J Med Res. 2009; 129:472-477.

[2]. Marry C.J.L.and S.S Loezard. Mortality by cause for eight region of the world. Global burden of disease study. Lancet 1997; 349:1269-1276.

[3]. Rao CR, Kamath VG, AvinashShetty A, Kamath A. High blood pressure prevalence and significant correlates : A quantitative analysis from Coastal Karnataka, India. ISRN Preventive Medicine 2013; 1:1-6.

[4]. The WHO statistics $2012 \quad$ report, $\quad$ Geneva, $\quad$ published 2012.www.who.int/.../publications/world_health_statistics/EN_WHS2012_Full.pdf.

[5]. Kulkarni A.T. Hypertension - A silent killer. India medical Gazette. 1998; 32(3):73-77.

[6]. Bharati DR, Nandi P, Yamuna TV et al. Prevalence and Covariates of Undiagnosed Hypertension in the Adult Population of Puducherry, South India. Nepal Journal of Epidemiology 2012; 2(2):191-99.

[7]. Gupta R. "Meta analysis of prevalence of hypertension in India. Dept. Of Med. Monilek hospital \& Research centre Raipur. Heart Journal. 1997; 49(1): 43(18).

[8]. S.S. Reddy, G.R. Prabhu. Prevalence \& risk factors of hypertension among adults of urban slum of channa Reddy colony in Tirupati Town, A.P. Indian J Com Med. 2009; 30(3).

[9]. Madukumar S, Gaikwad V and Sudeepa D. Epidemiological study of hypertension and its risk factor in rural population of Bangalore district. Al Ameen J Med Sc. 2012; 5(3): 264-270.

[10]. Seedat y. K, Seedat M. A and Reddy K. Prevalence of hypertension in Indian population of Durban. S. African Med J. 1978; 54(1): 10-5.

[11]. Desai R, Dhruv P, Marwadi M et al. Prevalence and correlates of hypertension in slum population of Surat city. National J Med Research.2012; 2(381)

[12]. Makwana N, Shah V, Khambhati S, Choudhary M, Goswami K, Yadav S. Assessment of risk factors of hypertension: A crosssectional study. Journal of Evolution of Medical and Dental Sciences 2012 October; 1(4):519-26.

[13]. Ali SH. An epidemiological study of hypertension and diabetes with special reference to alcohol and tobacco addiction and treatment compliance in above 40 years age group in a slum area of Chennai. Journal of Evolution of Medical and Dental Sciences 2012 Jan- March; 1(1):9-15.

[14]. Joshi SV, Patel JC, Dhar HL. Prevalence of hypertension in Mumbai. Indian J Medical Sci 2000; 54:380-83.

[15]. Bharucha NE, Kuruvilla T. Hypertension in the Parsi community of Bombay: a study on prevalence, awareness and compliance to treatment. BMC Public Health 2003; 3:11-15.

[16]. Chaturvedi S, Pant M, Neelam, Yadav G. Hypertension in Delhi: prevalence, awareness, treatment and control. 2007 Jul 37(3):142-5. 